\title{
Antibiotic treatment of Clostridium difficile infection in children - a challenge in pediatric practice
}

\author{
Gabriela Leşanu', Cristina Becheanu', Raluca Maria Vlad ${ }^{1 *}$, Daniela Lemeni ${ }^{2}$, loana Sabina Macovei², \\ Daniela Păcurar', Mirela Stocklosa', Irina Andronie', Alexandra Moraru ${ }^{1}$ \\ From The 10th Edition of the Scientific Days of the National Institute for Infectious Diseases "Prof Dr Matei \\ Bals" \\ Bucharest, Romania. 15-17 October 2014
}

\section{Background}

In the last decade the incidence of Clostridium difficile infection (CDI) in children is progressively increasing and the pediatricians are faced with difficulties in the therapeutic approach.

\section{Methods}

We performed a retrospective study that analyzed the antibacterial treatment in CDI from the experience of a Pediatric Gastroenterology Department - Grigore Alexandrescu Clinical Children's Emergency Hospital, Bucharest. Cases were identified through enzyme immunoassays for A toxin or for A and B toxin of Clostridium difficile in the stool.

\section{Results}

Between January $1^{\text {st }} 2005$ and July $31^{\text {st }} 2014,52$ patients were diagnosed with CDI. A large number of cases $(61 \%)$ were diagnosed in the age group 1 to 4 years. The sex ratio was $M / F=0.9 / 1.36 \%$ of patients had communityacquired CDI. In mild/moderate forms metronidazole was administered as a first-line treatment in 32 (61\%) cases and proved efficient in $25 / 32$ (78.1\%) cases; vancomycin was used and was efficient in 18 cases. In severe forms (7.7\%), the association of intravenous metronidazole and oral vancomycin was the option of choice and this approach cured all these cases. We report 11 patients with recurrent CDI (21\%); in these cases oral vancomycin was efficient for the treatment of the recurrence. In 3 cases with a second recurrence rifaximin was the chosen therapy. Six out of 11 children with recurrent CDI had comorbidities (Hirschsprung disease, ulcerative colitis).

\section{Conclusion}

The majority of patients in the study group were 1 to 4 years aged children. One third of patients had community-acquired CDI. We consider that the failure rate for metronidazole treatment is small and thereby metronidazole may be recommended for the treatment of the first episode of mild/moderate CDI. The association of intravenous metronidazole and oral vancomycin remains the treatment of choice for severe cases.

Authors' details

'Grigore Alexandrescu Clinical Children's Emergency Hospital, Bucharest, Romania. ${ }^{2}$ Cantacuzino National Institute for Research and Development for Microbiology and Immunology, Bucharest, Romania.

Published: 15 October 2014

\section{doi:10.1186/1471-2334-14-S7-P6}

Cite this article as: Leşanu et al:: Antibiotic treatment of Clostridium difficile infection in children - a challenge in pediatric practice. BMC Infectious Diseases 2014 14(Suppl 7):P6.

\footnotetext{
* Correspondence: ralu_neagoe@yahoo.com

'Grigore Alexandrescu Clinical Children's Emergency Hospital, Bucharest,

Romania

Full list of author information is available at the end of the article
} 